\title{
Numerical Parametric Study on the Cyclic Performance of Trapezoidally Corrugated Steel Shear Walls
}

\author{
Ali Joharchi", Siti Aminah Osman, Mohd Yazmil Md Yatim, Mohammad Ansari \\ Department of Civil Engineering, Universiti Kebangsaan Malaysia, UKM, 43600 Bangi, Selangor, Malaysia
}

Received December 29, 2020; Revised March 1, 2021; Accepted March 12, 2021

\section{Cite This Paper in the following Citation Styles}

(a): [1] Ali Joharchi, Siti Aminah Osman, Mohd Yazmil Md Yatim, Mohammad Ansari, "Numerical Parametric Study on the Cyclic Performance of Trapezoidally Corrugated Steel Shear Walls," Civil Engineering and Architecture, Vol. 9, No. 2, pp. 462-476, 2021. DOI: 10.13189/cea.2021.090219.

(b): Ali Joharchi, Siti Aminah Osman, Mohd Yazmil Md Yatim, Mohammad Ansari (2021). Numerical Parametric Study on the Cyclic Performance of Trapezoidally Corrugated Steel Shear Walls. Civil Engineering and Architecture, 9(2), 462-476. DOI: 10.13189/cea.2021.090219.

Copyright $\bigcirc 2021$ by authors, all rights reserved. Authors agree that this article remains permanently open access under the terms of the Creative Commons Attribution License 4.0 International License

\begin{abstract}
Corrugated steel shear wall (CSSW) has higher ductility, energy dissipation capacity and toughness compared to the conventional steel plate shear wall (SPSW). The corrugation steel plate can be either installed vertically or horizontally. In recent decades, several experimental and numerical studies have investigated the effect of the corrugation angle, infill plate thickness and openings on the cyclic behavior of the horizontally-corrugated steel shear walls. However, to date, the behavior of the vertically-corrugated steel shear walls has not been fully studied. Thus, this paper aims to investigate numerically the cyclic behavior of the vertically-corrugated steel shear walls. The corrugation angle $\left(30^{\circ}-120^{\circ}\right)$, infill plate thickness $(1.25,2,3 \mathrm{~mm})$, and the height-to-width $(\mathrm{H} / \mathrm{B})$ ratios of the walls $(0.5,0.8$, and 1.2) were the parameters of this study. The influence of these parameters on the hysteresis behavior, toughness, and energy dissipation capacities of the CSSWs are investigated using 35 finite element (FE) models developed by ABAQUS/Standard. The FE results reveal that increasing the corrugation angle can improve the energy dissipation capacities and toughness of the CSSWs up to $15 \%$ and $5.8 \%$, respectively. Furthermore, increasing the infill plate thickness and decreasing $\mathrm{H} / \mathrm{B}$ ratios can significantly enhance the ultimate load, toughness, and energy dissipation capacities.
\end{abstract}

Keywords Cyclic Loading, Corrugated Steel Shear Wall, Energy Dissipation Capacity, Finite Element

\section{Introduction}

The performance of Steel plate shear walls (SPSW) considerably depends on the infilled steel plate. Several kinds of research have shown that using stiffened and unstiffened steel plates can affect the load capacity, ductility, and energy dissipation capacity of the steel walls [1-12]. Using corrugated steel plates, in the shape of trapezoids, as stiffened infilled steel plates has been of interest to researchers [13-26]. The influence of different parameters such as corrugation shape, corrugation angle, and opening size, and position on the behavior of the corrugated steel shear walls (CSSW) have been investigated through several experimental and numerical studies. In the case of trapezoid-shaped corrugated steel plates, Emami et al. [13] studied the behavior of CSSWs with horizontally and vertically corrugated steel plates under cyclic loading experimentally. The experimental program included two specimens: horizontally and vertically corrugated steel plates with a corrugation angle of $30^{\circ}$ and an unstiffened specimen. The results showed that the stiffened specimens achieved higher energy dissipation capacity, ductility, and initial stiffness compared to the unstiffened specimen. However, the load capacity of the unstiffened specimen was approximately $17 \%$ higher than those of CSSWs.

Following the experimental work done by Emami et al. [13], finite element analysis (FEA) studies were conducted to investigate the cyclic behavior of CSSWs with various corrugation angles and the thickness of the horizontally corrugated infilled plate $[17,18,21]$. The FEA 
results of CSSWs with corrugation angles of 30, 45, 60, and 90 showed that increasing corrugation angle enhanced the energy dissipation and cyclic behavior of the CSSWs. In addition, FEA results revealed that the thickness of the infilled steel plates has a great influence on the strength and stiffness of the CSSWs [17,18,21].

In the case of CSSWs with vertically corrugated steel plates, Hosseinzadeh et al. [16] conducted another experiment using the cyclic behavior of CSSWs with different corrugation angles of vertical infilled plates. Three specimens with an infilled plate thickness of 1.25 $\mathrm{mm}$ and various corrugation angles were of $30^{\circ}, 45^{\circ}$, and $60^{\circ}$. The results showed that contrary to a horizontally corrugated steel infilled plate, increasing the corrugation angle decreased the energy dissipation capacity and stiffness of the CSSWs. Furthermore, the load capacities of the CSSWs decreased by increasing the corrugation angle.

Despite the available experimental data for CSSWs with vertically corrugated steel plates, the cyclic behavior of CSSWs with vertically corrugated steel plates has not been well studied. The effect of infilled plate thickness was not included in the experimental results. In addition, only three corrugation angles were considered in the experimental tests. Furthermore, the theoretical formulae provided by Emami et al. [13] showed that the load capacity of the CSSWs is affected by the height and width of the infilled plate, which has not been studied so far. Thus, the current research intends to investigate numerically the effect of corrugation angle, height-to-width ratios of the wall, and infilled plate thickness on the cyclic behavior of the CSSWs with vertically corrugated steel plate.

\section{Finite Element Modeling}

\subsection{Model Description}

Nonlinear FE analysis was employed to study the behavior of CSSWs under cyclic loading using ABAQUS/Standard software. The specifications and the material properties of all the components of the FE model used in this study were adopted from the experimental test specimen (Sample No. 2) conducted by Emami et al. [13]. The test specimen consists of a boundary frame and an infilled corrugated steel plate, which was corrugated in the direction of the frame span. The boundary was made of I-sections including HEB140, HEB200, and HEB160 that were used for the top beam, bottom beam, and columns, respectively. Additionally, the frame components were reinforced by stiffener plates as detailed in Fig. 1a. The infilled panel was made of a steel plate with a thickness of $1.25 \mathrm{~mm}$, which were corrugated into trapezoids with a corrugation depth and flat width of $50 \mathrm{~mm}$ and $100 \mathrm{~mm}$, respectively, as they are shown in Fig. 1 b.

\subsection{Mechanical Properties and Constitutive Model of Steel Material}

An isotropic bilinear stress-strained relationship with similar properties in both tension and compression was taken into account for the steel material. The yield criteria of Von Mises were used to specify the material yield surface, as well as a related flow rule to evaluate the plastic deformation. The properties of the steel components are presented in Table 1. They were adopted from the experimental test [13]. The steel Poisson's ratio was considered to be 0.3 .

Table 1. The mechanical properties of the steel components

\begin{tabular}{|c|c|c|c|c|c|}
\hline Type & $\begin{array}{c}\text { Young's } \\
\text { Modulus } \\
\mathrm{E} \\
(\mathrm{GPa})\end{array}$ & $\begin{array}{c}\text { Yield } \\
\text { stress } \\
\mathrm{f}_{\mathrm{y}} \\
(\mathrm{MPa})\end{array}$ & $\begin{array}{c}\text { Ultimate } \\
\text { Stress } \\
\mathrm{f}_{\mathrm{u}} \\
(\mathrm{MPa})\end{array}$ & $\mathrm{f}_{\mathrm{y}} / \mathrm{f}_{\mathrm{u}}$ & $\begin{array}{c}\text { Elongation } \\
(\%)\end{array}$ \\
\hline Plate & 210 & 207 & 290 & 0.71 & 41 \\
\hline Column & 210 & 300 & 443 & 0.67 & 33 \\
\hline Beam & 210 & 288 & 456 & 0.63 & 37 \\
\hline
\end{tabular}


(a)

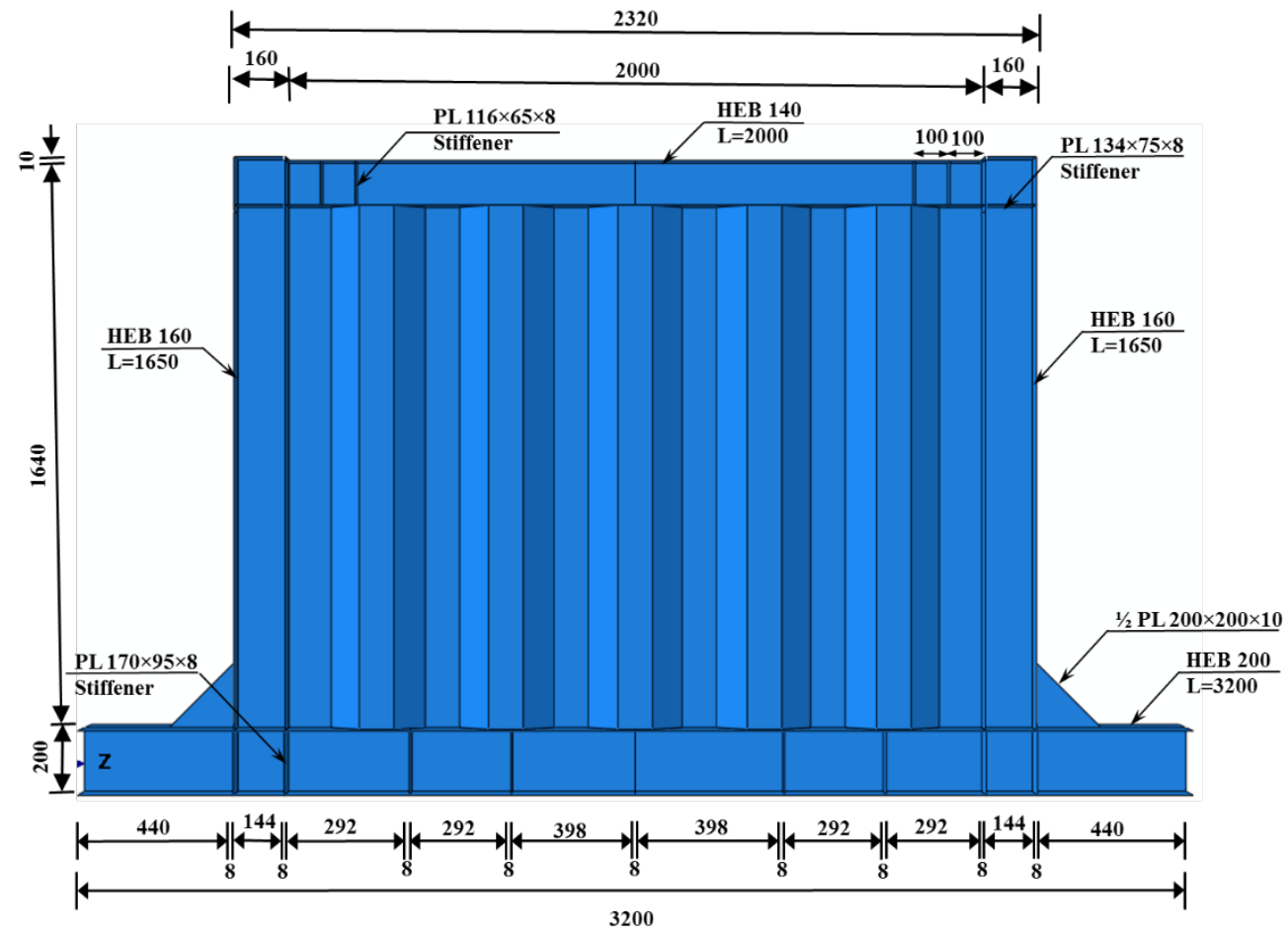

(b)

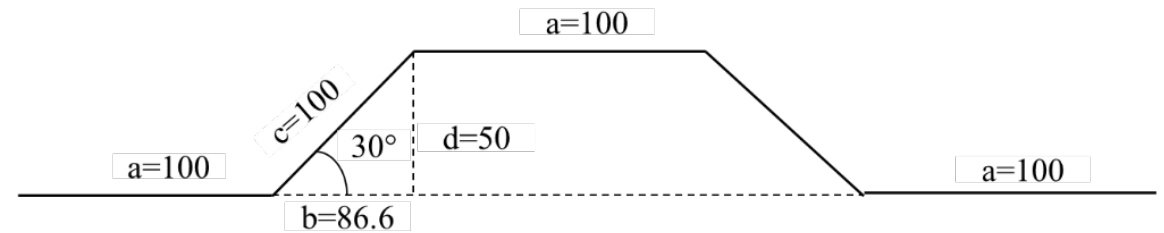

Figure 1. Details of FE model (unit: $\mathrm{mm}$ ) (a) The Boundary Frame Details; (b) Infilled Panel with a Corrugation Angle of $30^{\circ}$

\subsection{Elements Description}

Linear 4-node shell element (S4R) was chosen for all components of the model, with three translational and three rotational degrees of freedom. This element has been adopted in several FE analysis pieces of research $[5,7,16]$ and it could represent the-out-o- plate buckling of the infilled panel and plastic deformation of the boundary frame precisely.

\subsection{Surface Interaction}

According to the experimental test, the frame components of the test specimen were welded to each other. The connection between the infilled panel and the frame was provided by vertical steel plates, which had been welded to the frame and also attached to the flat part of the corrugated steel plate by using bolts and welding. To simplify the connections of the FE model, the steel plates, bolts and welding were replaced by tie constraint available in ABAQUS, which considered as fully bond connection between all the components of the models. This constraint allows no slip and separation between the components. The presumption of no separation and slip between the FE model components was well matched with the experimental study since all the components of the test specimen were welded and no failure in the connections was reported [13].

\subsection{Boundary Condition and Loading Program}

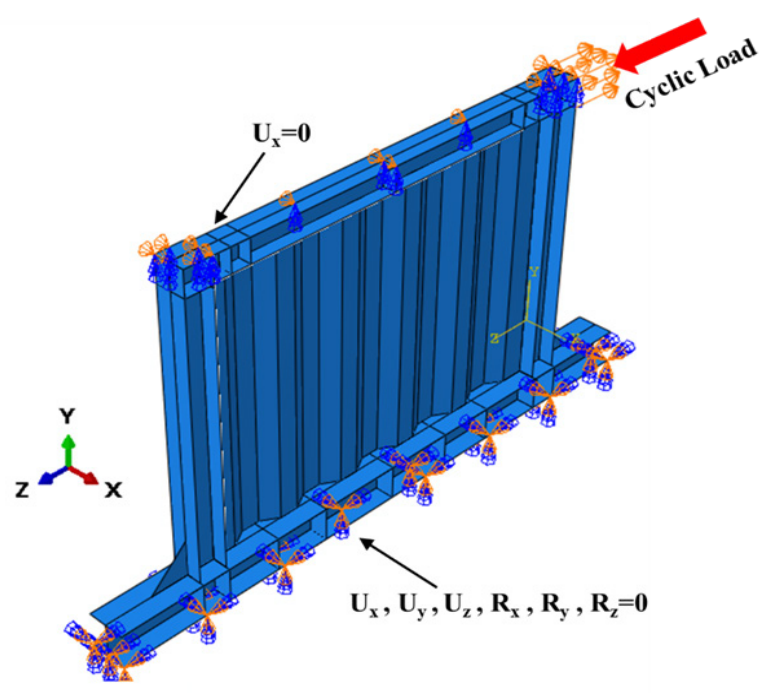

Figure 2. The boundary conditions of the FE model 
The connection between the base beam and the rigid floor in the experimental pro-gram was defined in FE model using fixed support assigned to all nodes of the base beam's bottom flange, which restrained the nodes from translation and rotation in all directions. Furthermore, the top beam of the test specimen was laterally braced to avoid out-of-plane displacement. This scenario was simulated in the FE models by limiting the translation of the nodes on the top flange of the top beam in X-direction. To simulate the horizontal cyclic load, a displacement load with tabular amplitude in the Z-direction was assigned to a node region on the exterior column flange at top of the frame. Fig. 2 and Fig. 3 indicate the boundary conditions of the FE model, and the cyclic displacement load consequences used in the FE model, respectively.

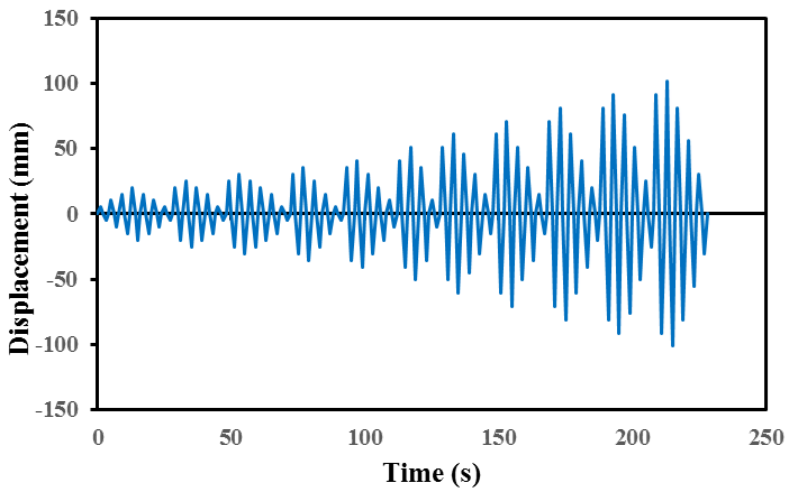

Figure 3. Cyclic displacement load consequences of the FE model

\subsection{Analysis Method}

General static step available in ABAQUS/Standard was selected to conduct the nonlinear FE analysis. The geometrical nonlinearity was taken in account to obtain the nonlinear behavior of the FE model. In this study, the period time of each load cycle was set to $4 \mathrm{~s}$, which was adopted from other numerical study [27]. Thus, the total time of cycles was $228 \mathrm{~s}$. The automatic incrimination with an increment size of $0.1 \mathrm{~s}$ was considered for the initial and maximum phases of the step to achieve smooth and uniform increments as well as avoiding the convergence problems [27]. The entire computing time was about 189 minutes with computer having core i7 CPU and 8 GB RAM.

\subsection{Meshing Convergence Study}

A convergence research was undertaken for the numerical analysis of the CSSWs to validate the correct meshing scale for the proposed FE models. The ultimate load capacity of five FE models with specific number of elements was compared to the experimental result [13].
No major difference was found between the load values of the last three iterations, with a total of components 2835 , 3153, and 3403 respectively as shown in Fig. 4. However, the model of 3153 elements was chosen to reflect the FE models in this analysis since this software requires a fair amount of system running time on a standard PC.

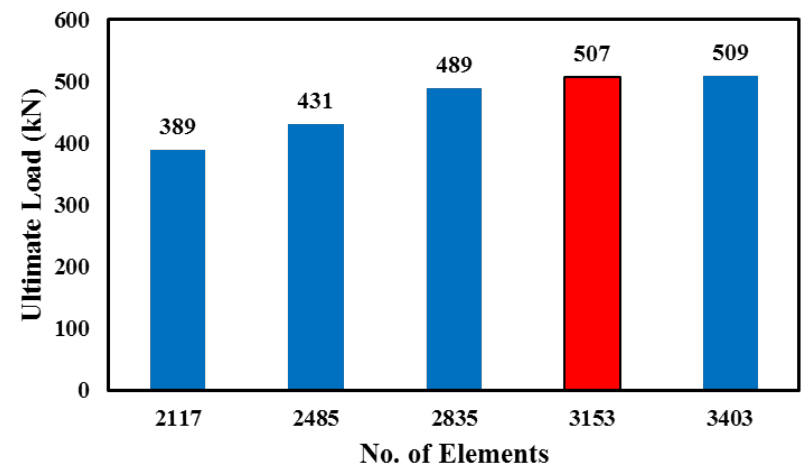

Figure 4. Meshing Convergence Study

\subsection{The Validity of FE Model}

The accuracy of the FE model was verified by comparing the lateral load vs dis-placement hysteresis results and failure mode of $\mathrm{FE}$ analysis in addition to the corresponding experimental test results.

Fig. 5 compares the lateral load vs displacement hysteresis results of the FE analysis and the experimental test. From Fig. 5, the hysteresis loops of the FE analysis were well matched with those of the experimental test. Table 2 presents comparisons between the FE and experimental results. The ultimate lateral load of the $\mathrm{FE}$ analysis and the experimental test were 507 and $500 \mathrm{kN}$, respectively, which demonstrates only $1 \%$ overestimation in the FE analysis result. Moreover, the energy dissipation capacity and toughness of the FE model were $1 \%$ and $2 \%$ greater than those of the experimental specimen, respectively, which shows the ideal accuracy of the proposed model.

Fig. 6 displays the deformed shape of the FE model. Severe buckling of the infill plate was observed in both the experimental test and FE results. In addition, the buckling of triangular plates was also observed in both $\mathrm{FE}$ result and the experimental test.

Table 2. The comparison between the experimental and FE analysis results

\begin{tabular}{|c|c|c|c|}
\hline Parameter & $\begin{array}{c}\text { Experimental } \\
\text { test }\end{array}$ & $\begin{array}{c}\text { FE } \\
\text { analysis }\end{array}$ & FE/EX \\
\hline Ultimate load (kN) & 500 & 507 & 1.01 \\
\hline $\begin{array}{c}\text { Energy dissipation } \\
\text { capacity (kN.m) }\end{array}$ & 990 & 1002.4 & 1.01 \\
\hline Toughness (kN.m) & 42.3 & 43.1 & 1.02 \\
\hline
\end{tabular}




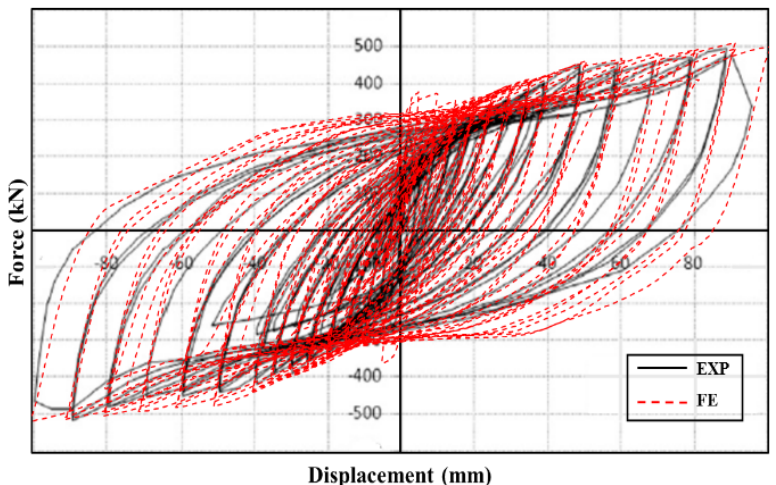

Figure 5. Meshing Convergence Study

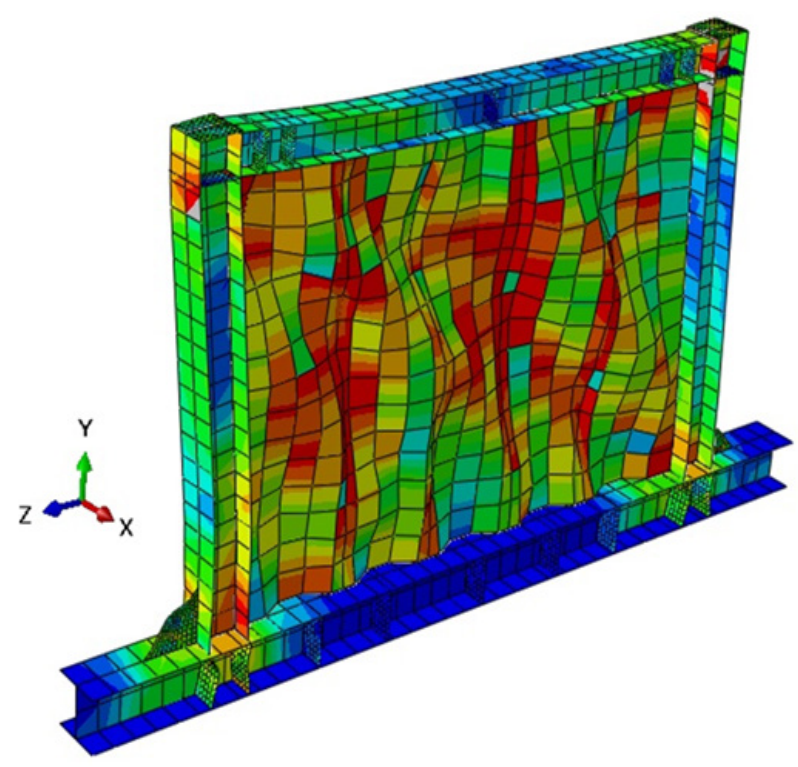

Figure 6. The deformed shape of the validated model

\section{Parametric Studies}

Parametric studies were performed using the results of thirty-five FE models to investigate the effects of corrugation angle $(\theta)$, infill plate thickness $\left(\mathrm{t}_{\mathrm{w}}\right)$, and height-to-width ratio $(\mathrm{H} / \mathrm{B})$ on the behavior of CSSWs under cyclic load. The height and width of the model are considered as the distance between the outer surfaces of the top and bottom beams' flanges, and the distance between the outer surfaces of the columns' flanges, respectively. To identify the model specifications easily, the corrugated angle, infill plate thickness and height-to-width ratio were included in the labeling system used for FE models. The model label starts with the letter "C" and is followed by three numbers, which represent corrugation angle, infill plate thickness and height-to-width ratio, respectively. For example, C30-1.25-0.8 express the model with $\theta, \mathrm{t}_{\mathrm{w}}$ and $\mathrm{H} / \mathrm{B}$ equal to $30^{\circ}, 1.25 \mathrm{~mm}$, and 0.8 , one after another.

\subsection{The Effects of Corrugation Angle}

The effect of infill plate corrugation angle on the hysteretic behavior, energy dissipation capacity, and toughness of CSSWs were studied using seven FE models. The corrugation angles ranged from $30^{\circ}$ to $120^{\circ}$ with an increment of $15^{\circ}$. The corrugation depth and flat width of the infill panel were maintained $50 \mathrm{~mm}$ and $100 \mathrm{~mm}$ for all the models, respectively. Thus, only the inclined width of the panel varied by changing the corrugation angle. The height-to-width ratio of the models and thickness of the infill panel were similar to the experimental model and equaled to 0.8 and $1.25 \mathrm{~mm}$, respectively.

Fig. 7 shows the hysteresis curves of the FE model with various corrugation angles. The results indicate that increasing the corrugation angle reduced the pinching of the loops and resulted in wider and more stable loops. However, the ultimate loads of the models with increasing the corrugation angle from $30^{\circ}$ to $60^{\circ}$ decreased and then with further raising the corrugation angle to $120^{\circ}$, the ultimate load of the models increased, as it is shown in Fig. 8. The reduction in the ultimate strengths of CSSWs with corrugation angles of $45^{\circ}$ and $60^{\circ}$ had also been reported in the previous experimental study [16]. It is observed from Fig 8 that C60-1.25-0.8 achieved its ultimate load of $421.2 \mathrm{kN}$ that was $16.9 \%$ lower compared to that of $\mathrm{C} 30-1.25-0.8$, whereas the difference between the ultimate loads of C30-1.25-0.8 and C120-1.25-0.8 was only $0.2 \%$.

The reduction in the ultimate loads of the FE models by increasing the corrugation angle is related to the shear stress distribution in the infill plates of the models as shown in Fig. 9. The shear stress induced in the infill plate is the summation of the critical buckling shear stress $\left(\tau_{\mathrm{cr}}\right)$ and tension field stress $\left(\sigma_{\mathrm{ty}}\right)$ [13]. The ultimate shear strength of the infill plate can be determined from equation 1.

$$
V_{u}=L t\left(\tau_{c r}+1 / 2 \sigma_{t y} \sin 2 \alpha\right)
$$

where, $\alpha$ is tension field angle, $\mathrm{L}$ is total length of flat sub panel and $t$ is thickness of the infill plate.

Fig. 9 indicates that by increasing the corrugation angle from $30^{\circ}$ to $60^{\circ}$ the shear stress of the infill panel was reduced, since the inclination angle of the tension field $(\alpha)$ was increased. While, by increasing the corrugation angle from $60^{\circ}$ to $120^{\circ}$ the contribution of the infill plate enlarged. In other words, the larger area of infill plate gained high shear stress as a result of considerable growth of L. However, for the very thin infill plates, the effect of tension field stress is more pronounced in comparison with critical shear stress $\left(\tau_{\text {cr }}\right)$.

The energy dissipation capacity is an important seismic factor, which reflects the ability of the member in damping the seismic load and it is defined as the total area of the hysteresis loops. A code was written in MATLAB program to calculate the area of the hysteresis loops. Fig. 
10 compares the energy dissipation capacities of the models. It was observed that except C60-1.25-0.8 and C90-1.25-0.8, the energy dissipation capacity had been improved with escalating the corrugation angle.
C60-1.25-0.8 gained the lowest energy dissipation capacity, which was $4.2 \%$ lower than that of C30-1.25-0.8. Meanwhile, the energy dissipation capacity of C120-1.25-0.8 was 15\% higher than that of C30-1.25-0.8.
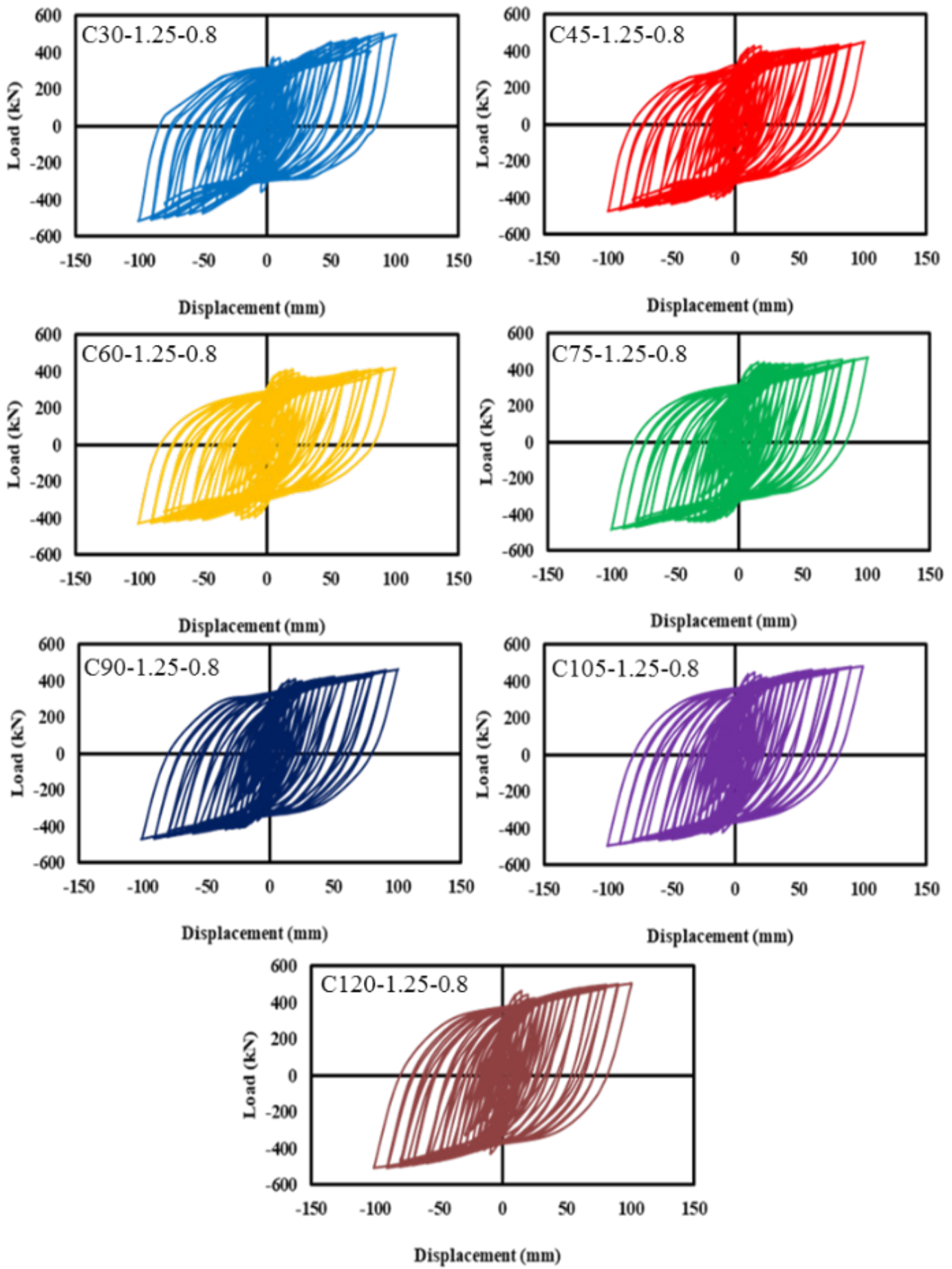

Figure 7. The hysteretic behavior of the FE models with various corrugated angles 


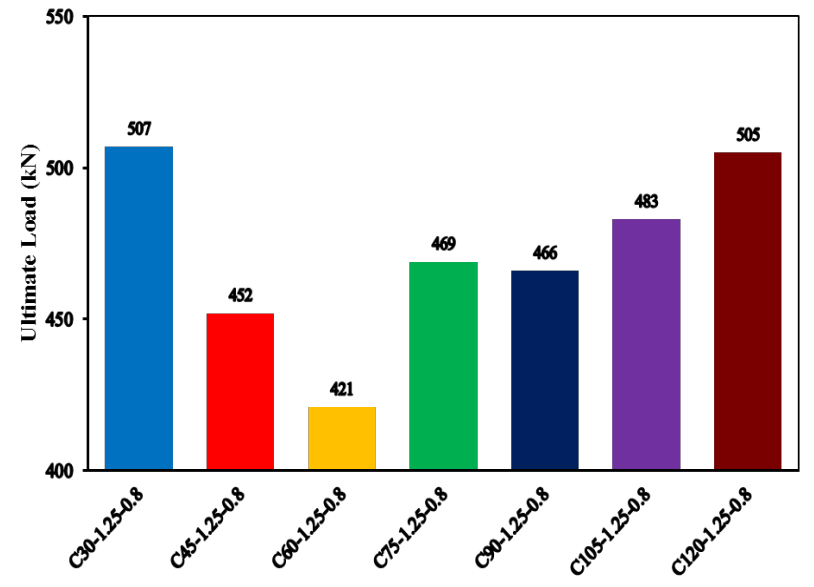

Figure 8. The ultimate loads of the FE models with various corrugation angles
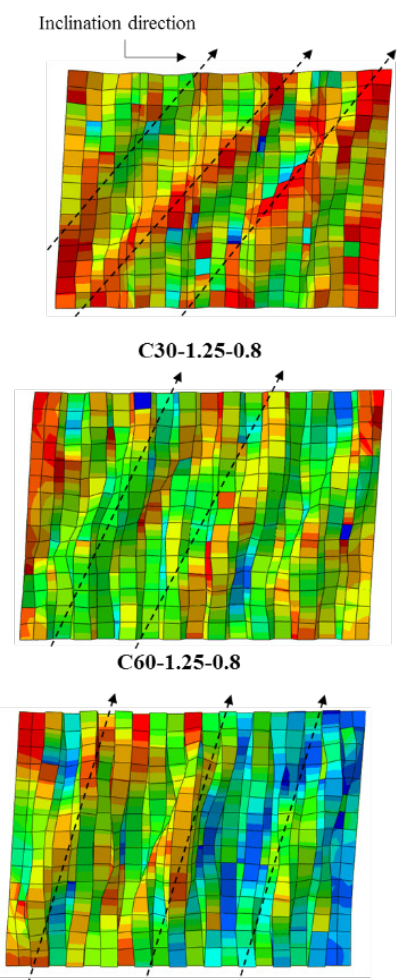

C90-1.25-0.8
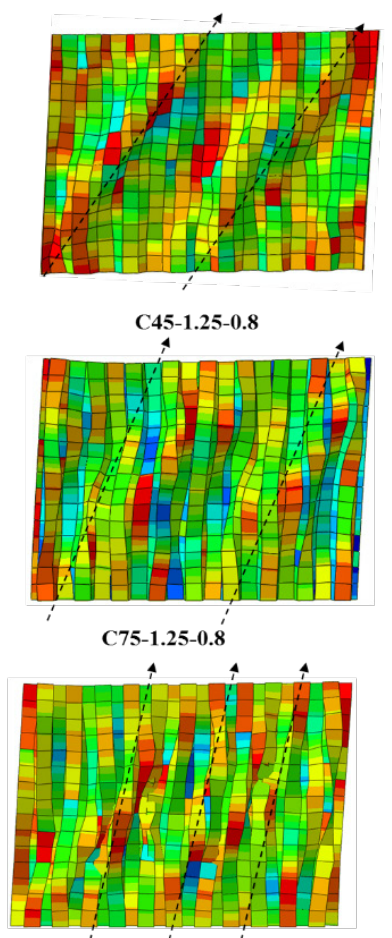

C105-1.25-0.8

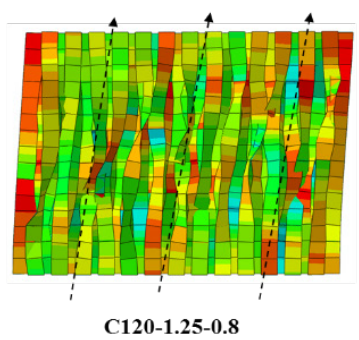

Figure 9. Shear stress contour for the models with different corrugation angle

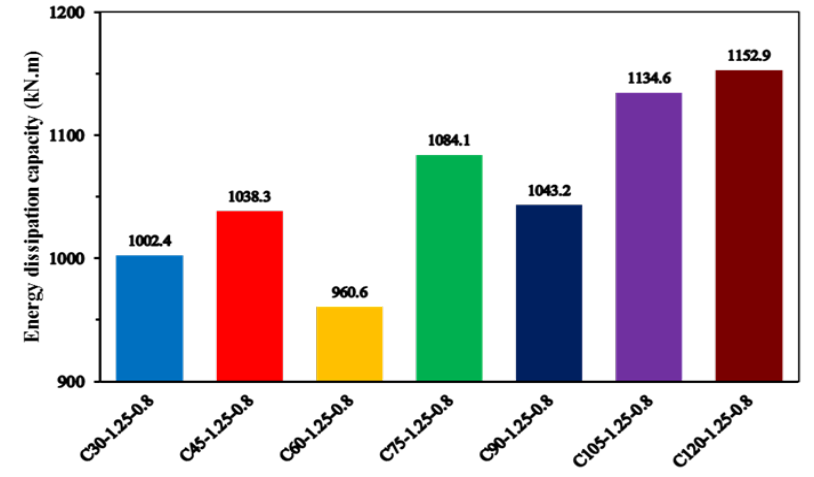

Figure 10. The energy dissipation capacities of FE models with different corrugation angle

The toughness is the capability of a structural member in absorbing energy to prevent failure under the effect of an external load, which is expressed as the area under the load-displacement response curve, which determined by the code developed by MATLAB program. The levels of models' toughness with various corrugation angles are compared in Fig. 11. It shows that the toughness of the models, similar to their energy dissipation capacities, decreased as the corrugation angle increased from $30^{\circ}$ to $60^{\circ}$, and then increased with changing the corrugation angle from $60^{\circ}$ to $120^{\circ}$. The toughness of C120-1.25-0.8 was $5.8 \%$ higher than that of $\mathrm{C} 30-1.25-0.8$.

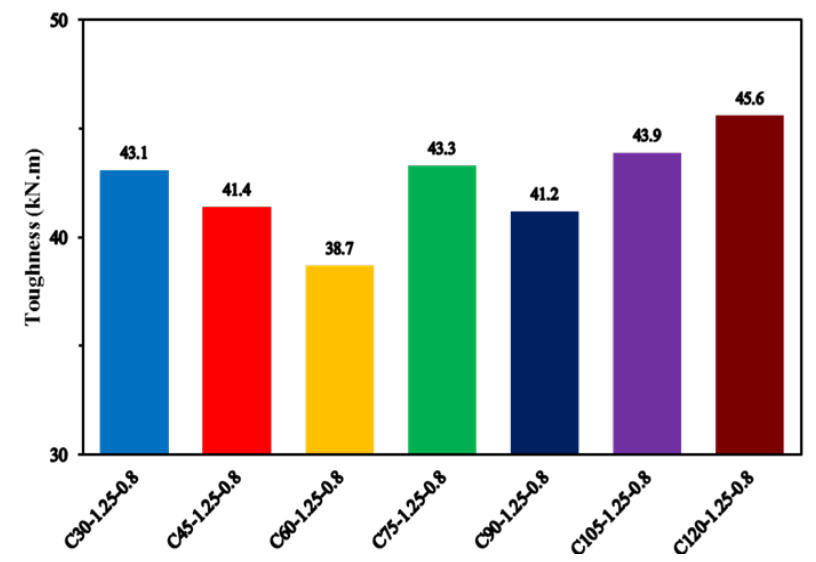

Figure 11. The toughness of FE models with different corrugation angles

\subsection{The Effects of Infill Plate Thickness}

The effects of infill plate thickness on the behavior of CSSWs were investigated using twenty-one FE models. The models had seven different corrugation angles which ranged from $30^{\circ}$ to $120^{\circ}$ (similar to the previous section) with three different infilled plate levels of thickness as following: $1.25 \mathrm{~mm}, 2 \mathrm{~mm}$ and $3 \mathrm{~mm}$. and finally the height-to-width ratios of the models equal to 0.8 . 
The load-displacement hysteresis curves of the FE models with an infilled plate thickness of $2 \mathrm{~mm}$ and $3 \mathrm{~mm}$ are shown in Fig.12. The results indicated a significant reduction in the pinching of the hysteresis loops of the model with infilled plate thickness of $2 \mathrm{~mm}$ and $3 \mathrm{~mm}$ in comparison with those with infilled plate thickness of 1.25 $\mathrm{mm}$. It was shown that a higher ultimate load, as depicted in Fig. 13, was the result of increasing the infilled plate thickness. Among the models with infilled plate thickness of $2 \mathrm{~mm}$, only C45-2-0.8 and C60-2-0.8 achieved their ultimate loads lower than $\mathrm{C} 30-2-0.8$. It was also found out that the ultimate load of the models with infilled plate thickness of $2 \mathrm{~mm}$ improved by raising the corrugation angle from $45^{\circ}$ to $120^{\circ}$. In case of the models with infilled plate thickness of $3 \mathrm{~mm}$, all the models gained greater ultimate loads compared to $\mathrm{C} 30-3-0.8$. Moreover, except for C60-3-0.8; improvements in the ultimate loads of these models could be seen when the corrugation angle was more. The ultimate load of $\mathrm{C} 120-3-0.8$ was $15.7 \%$ higher than that of C30-3-0.8.

The main reason of improving the ultimate load is associated with the buckling shear stress. $\tau_{\mathrm{cr}}$ is directly related to the infill plate thickness, as defined in Equation 2 [13,28], which can significantly be improved by increasing the infill plate thickness [28].

$$
\begin{gathered}
\frac{1}{\tau_{c r}}=\frac{1}{\tau_{c r, L}}+\frac{1}{\tau_{c r, G}} \\
\tau_{c r, L}=\frac{k \pi E}{12\left(1-v^{2}\right)}\left(\frac{t}{a}\right)^{2} \\
\tau_{c r, G}=36 \beta E\left[\left[(d / t)^{2}+1\right] / \eta\right]^{\frac{3}{4}}\left(\frac{t}{h}\right)^{2} / 12\left(1-v^{2}\right)
\end{gathered}
$$

where, E, v, d, h and a are the elastic modulus, Passion ratio, corrugation depth, infill panel height and the width of flat panel, respectively. $\beta$ and $\mathrm{k}$ are coefficients related to the boundary condition of the infill plate, and $\eta=(a+b) /(a+c)$.

It can be observed from Fig. 14 that the effect of the infilled plate thickness is more pronounced for the energy dissipation capacity. The models with infilled plate thickness of 2 and 3 prevented higher energy dissipation capacity, which was on average 2.1 and 3.2 times more than those models with infilled plate thickness of $1.25 \mathrm{~mm}$, respectively. From Fig. 14, C105-3-0.8 achieved the highest energy dissipation capacity with the value of 4211.4 kN.m, which had also the highest improvement in the energy dissipation compared to its corresponding model with the infilled plate thickness of $1.25 \mathrm{~mm}$.

The effect of the various infilled plate thickness on the toughness of the CSSWs is compared in Fig. 15. The results showed that increasing the infilled plate thickness from $1.25 \mathrm{~mm}$ to $2 \mathrm{~mm}$ enhanced the toughness of the models up to $46.4 \%$. From Fig. 15, C90-2-0.8 achieved the highest improvement in the toughness among the models with infilled plate thickness of $2 \mathrm{~mm}$. while increasing the infilled plate thickness from $1.25 \mathrm{~mm}$ to 2 $\mathrm{mm}$ did not have a noticeable effect on the toughness of the model with a corrugation angle of $45^{\circ}$. The comparison between the toughness of the models with infilled thickness of $3 \mathrm{~mm}$ shows that C120-3-0.8 gained the highest toughness. Nevertheless, C90-3-0.8 reached the highest progress in the toughness among the models with the infilled plate thickness of $3 \mathrm{~mm}$ when the infilled plate thickness differed from $1.25 \mathrm{~mm}$ up to $3 \mathrm{~mm}$. 

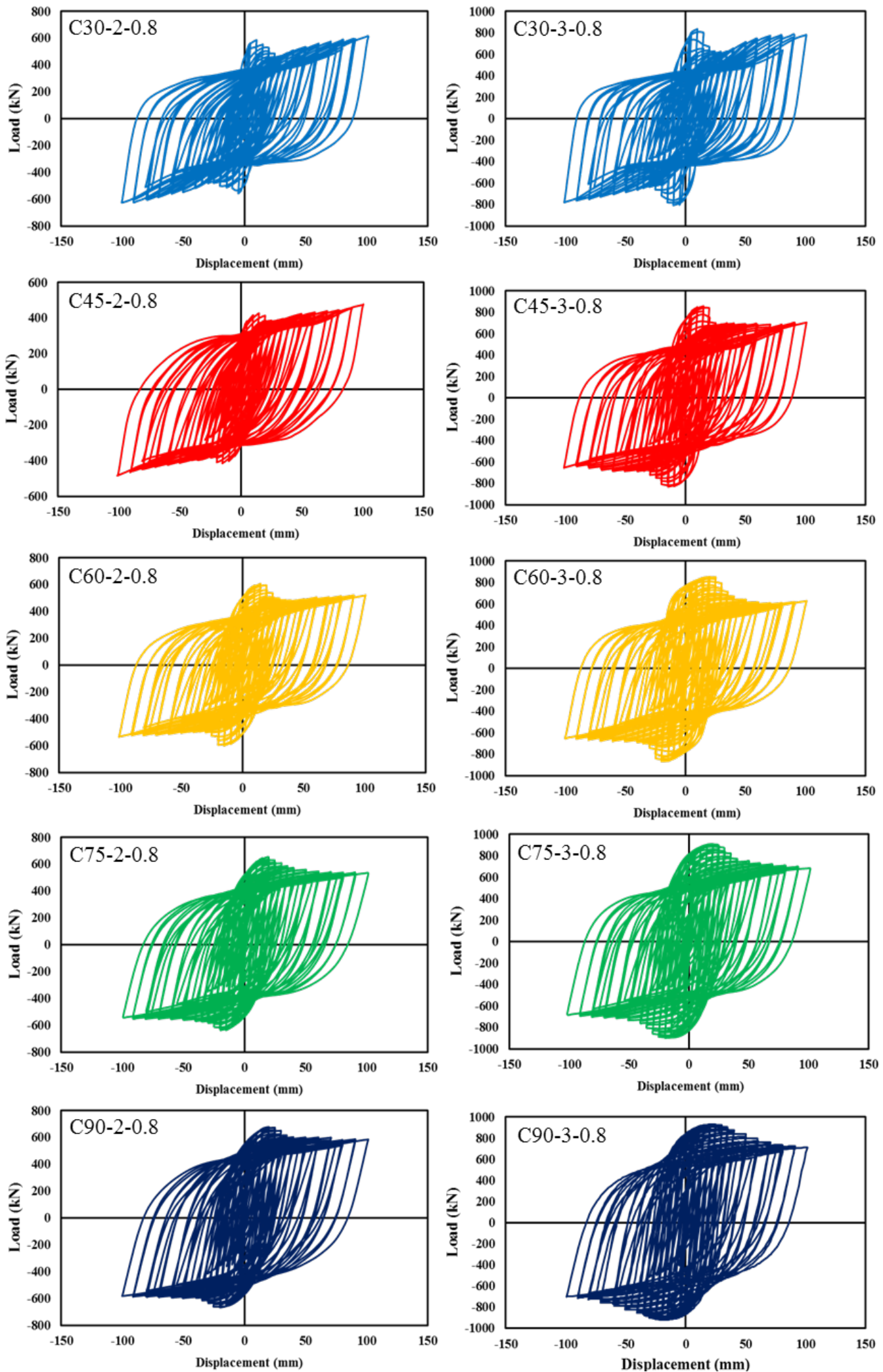

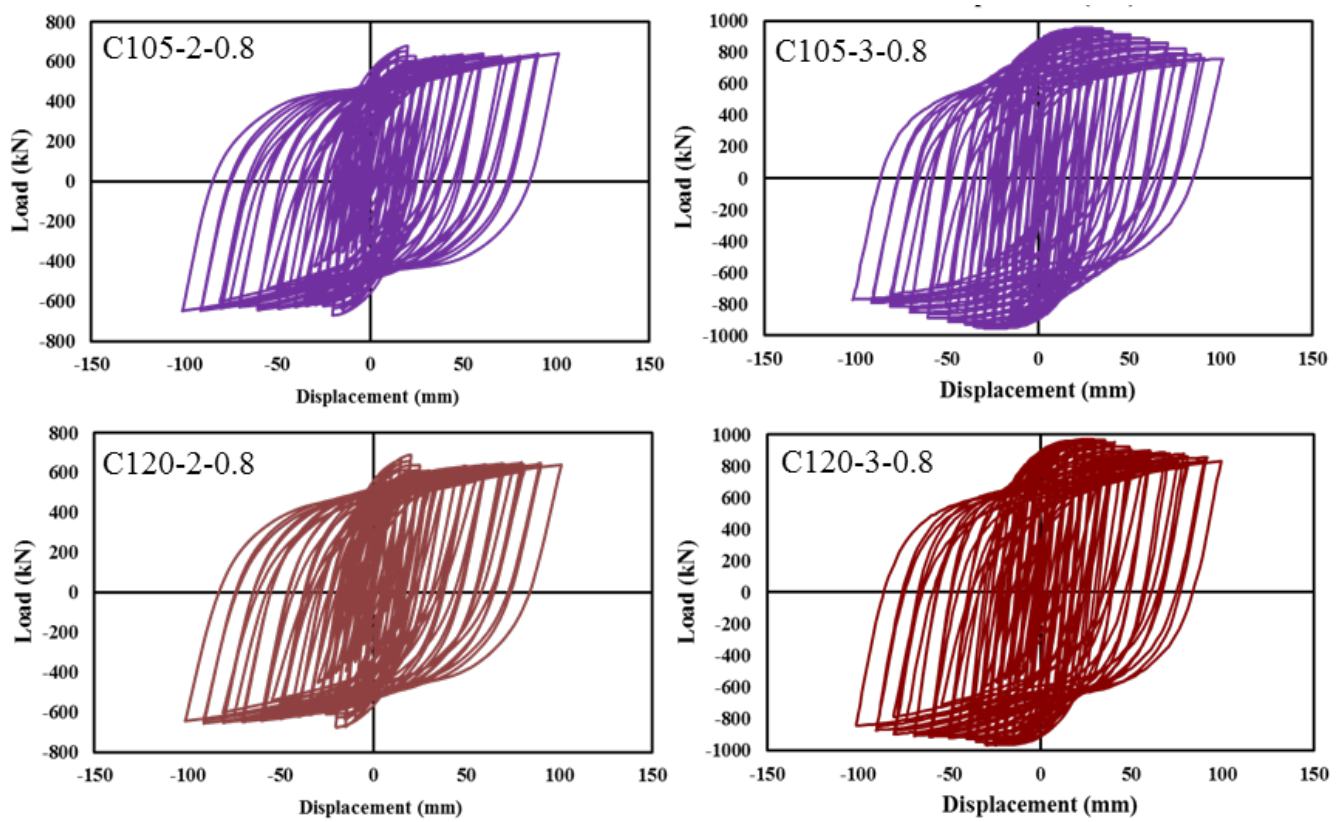

Figure 12. Hysteresis behavior of the FE models with different infill plate thickness

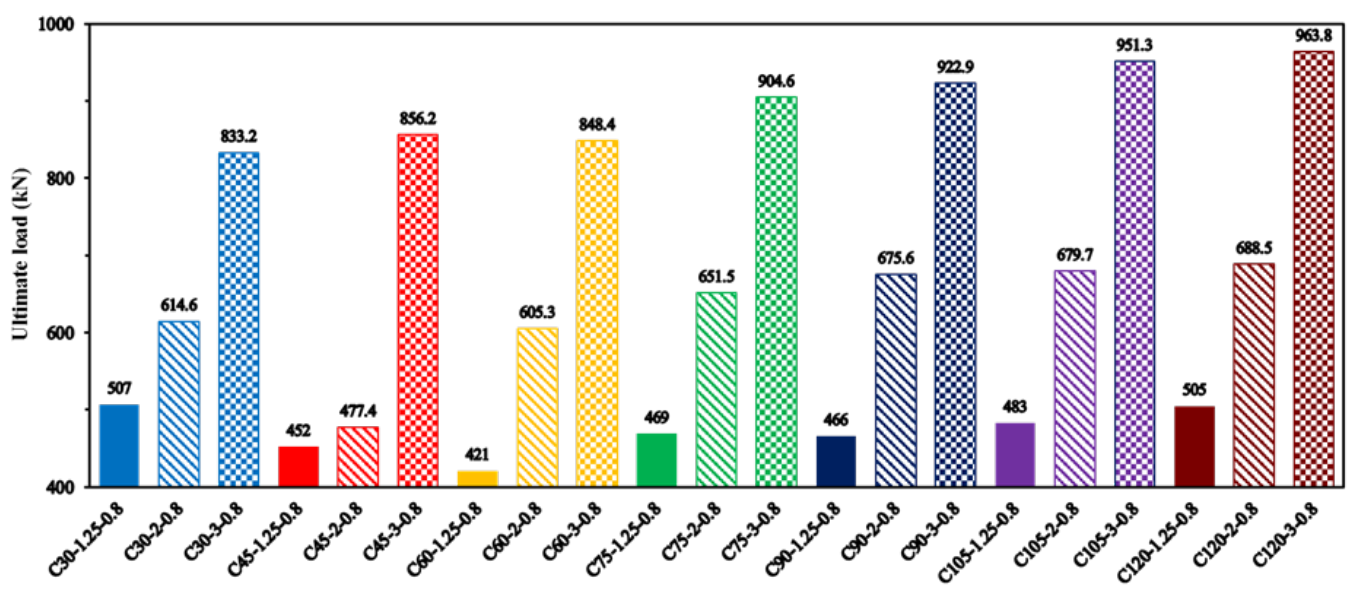

Figure 13. Ultimate loads of the FE models with different infill plate thickness

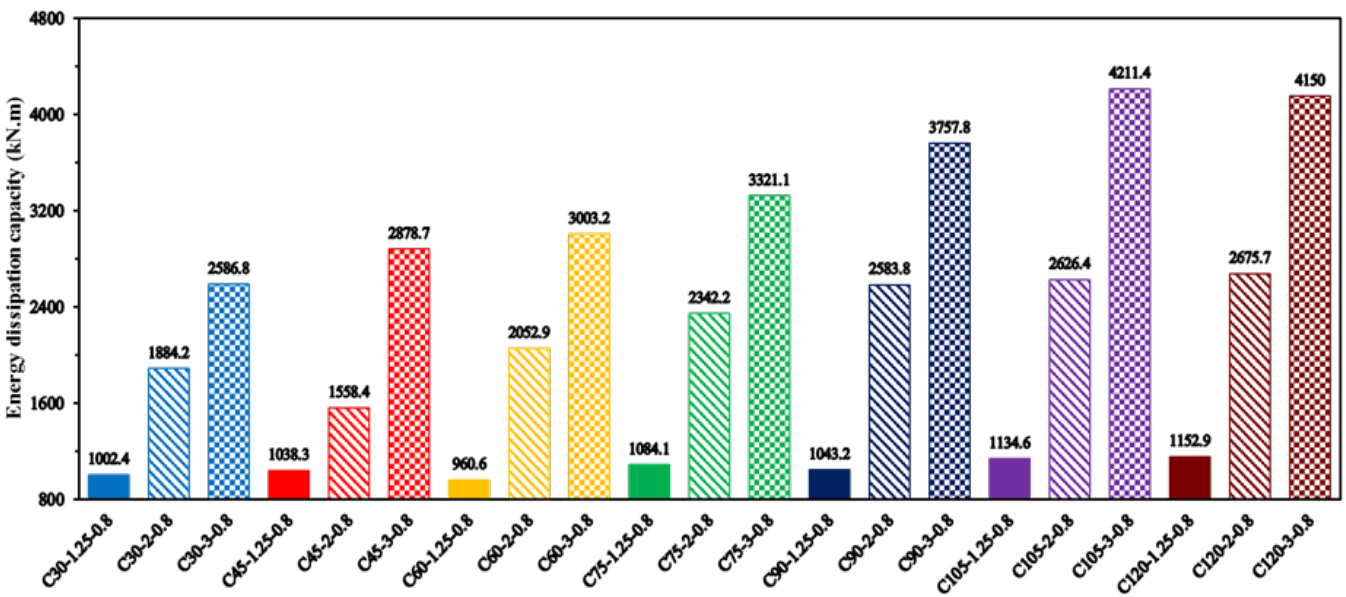

Figure 14. Energy dissipation capacities of the FE models with different infill plate thickness 


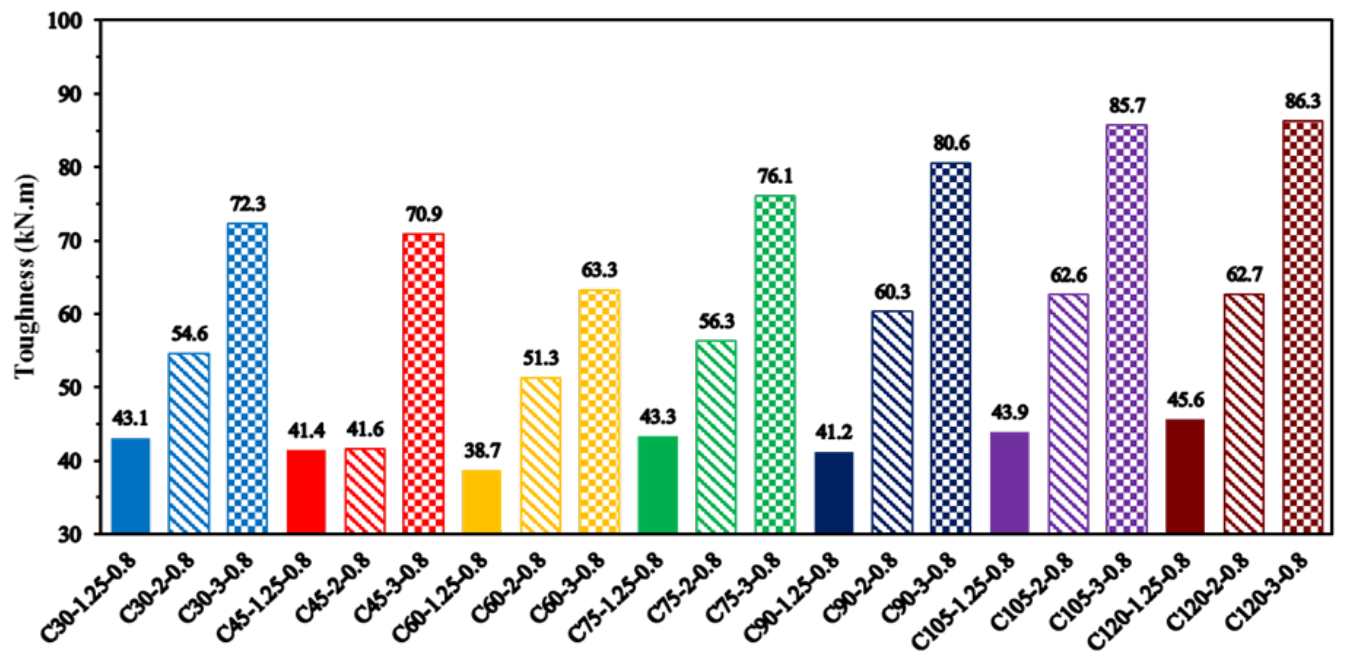

Figure 15. Toughness of the FE models with different infill plate thickness

\subsection{The Effects of Height-to-Width Ratio}

The effect of the height-to-width ratio was investigated using three $\mathrm{H} / \mathrm{B}$ ratios comprising $0.5,0.8$ and 1.2 . For this purpose, twenty-one models were used with the corrugation angles varied from $30^{\circ}$ to $120^{\circ}, \mathrm{H} / \mathrm{B}$ ratios of $0.5,0.8,1.2$, and the infilled plate thickness of $2 \mathrm{~mm}$. The $\mathrm{H} / \mathrm{B}$ ratios were applied to the models using a fixed height $(1850 \mathrm{~mm})$ and variable width. Thus, the width of the model related to the H/B ratios of $0.5,0.8$ and 1.2 were 3700,2320 and $1541 \mathrm{~mm}$.

Fig. 16 shows the load-displacement hysteresis curves of the FE models with $\mathrm{H} / \mathrm{B}$ ratios of 0.5 and 1.2. A reduction in the pinching of the hysteresis loops was observed as the $\mathrm{H} / \mathrm{B}$ ratio of the models was lowered. Due to increase of $\mathrm{L}$, the ultimate loads of the models got higher with decreasing the H/B ratio as illustrated in Fig. 17. In addition, the ultimate loads of the models with the $\mathrm{H} / \mathrm{B}$ ratio of 0.5 (except C105-2-0.5) were on the increase with raising the corrugation angle. In case of $\mathrm{H} / \mathrm{B}$ ratio of 1.2 , the ultimate loads of the models declined with increasing the corrugation angle from $30^{\circ}$ to $75^{\circ}$ and got more as the corrugation angle boosted from $75^{\circ}$ to $120^{\circ}$.

Lowering the $\mathrm{H} / \mathrm{B}$ ratio enhanced the energy dissipation capacity of the models as shown in Fig. 18. The comparison between the energy dissipation capacities of the models with the $\mathrm{H} / \mathrm{B}$ ratios of 0.5 and 0.8 shows that C45-2-0.5 gained the maximum improvement in the energy dissipation capacity as $\mathrm{C} 45-2-0.5$ achieved its energy dissipation capacities $71.6 \%$ higher compared to C45-2-0.8. Meanwhile, C90-2-0.8 gained the highest energy dissipation capacity among the models with $\mathrm{H} / \mathrm{B}$ ratio of 0.5 . Also, the comparison between the energy dissipation capacities of the models with the H/B ratios of 0.8 and 1.2 shows that $\mathrm{C} 90-2-0.8$ received the highest improvement in energy dissipation capacity as C90-2-0.8 achieved its energy dissipation capacity $108.8 \%$ higher than $\mathrm{C} 90-2-1.2$. Among the models with the $\mathrm{H} / \mathrm{B}$ ratio of 0.5, C90-2-1.2 and C120-2-1.2 eventually had the lowest and highest energy dissipation capacities.

Similar to the energy dissipation capacity, the toughness of the models enhanced when the $\mathrm{H} / \mathrm{B}$ ratio decreased as compared in Fig. 19. The results showed up to $73.8 \%$ improvement in the toughness of the models when the H/B ratio reduced from 0.8 to 0.5 . In addition, the toughness of the models enhanced up to $63.9 \%$ as the $\mathrm{H} / \mathrm{B}$ ratio decreased from 1.2 to 0.8 . On average, the toughness of the models changed positively up to $27.8 \%$ due to lowering of the $\mathrm{H} / \mathrm{B}$ ratio. It is observed from Fig. 19 that the models' toughness with $\mathrm{H} / \mathrm{B}$ ratio of 0.5 got more with increase of corrugation angle. From Fig. 19, C120-2-0.5 and C30-2-0.5 achieved the highest and lowest toughness with the values of $82.2 \mathrm{kN} . \mathrm{m}$ and 67.1 $\mathrm{kN} . \mathrm{m}$, which showed $22.5 \%$ improvement in the model toughness as corrugation angle increased from $30^{\circ}$ to $120^{\circ}$. For the models with the H/B ratio of 1.2, reduction in the models' toughness was experienced as the corrugation became higher from $30^{\circ}$ to $75^{\circ}$, and then the models' toughness made a progress with further increase of the corrugation angle. For example, the toughness of C30-2-1.2was $19.8 \%$ higher than C75-2-1.2, while the toughness of C120-2-1.2 was 7.6\% higher than C30-2-1.2.

\section{Conclusions}

In this study, numerical parametric measures were taken using thirty-five $\mathrm{FE}$ models to investigate the behavior of CSSWs under cyclic loading. The main parameters of the study were the corrugation angle variation $\left(30^{\circ}\right.$ to $\left.120^{\circ}\right)$, infilled plate thickness $(1.25,2$ and $3 \mathrm{~mm}$ ), and the height to width ratio of the shear wall $(0.5,0.8$ and 1.2). The behavior of CSSWs was discussed based on the hysteresis load-displacement curve, ultimate 
load, energy dissipation capacity, and toughness of the CSSWs. Following conclusions were drawn based on the findings of the study:

- The results showed that thicker infilled plate resulted in higher ultimate load, energy dissipation capacity and toughness. In addition, the effect of corrugation angle was found to be dependent on the infilled plate thickness. For infilled plate thickness of $1.25 \mathrm{~mm}$, increasing the corrugation angle from $30^{\circ}$ to $120^{\circ}$ was found out to be effective in case of energy dissipation capacity, toughness, and reducing pinching effect. However, the ultimate load of C30-1.25-0.8 was negligibly greater than $\mathrm{C} 120-1.25-0.8$. For infilled plate thickness of 2 and $3 \mathrm{~mm}$, the major improvement was found in the energy dissipation capacities of the models when the corrugation angle from $30^{\circ}$ reached to $120^{\circ}$. The energy dissipation capacities of C120-2-0.8 and C120-3-0.8 were $42 \%$ and $60.4 \%$ higher than those of $\mathrm{C} 30-2-0.8$ and C30-3-0.8, respectively. Besides, the findings of this study showed that the ultimate loads of the models with infilled thickness of 2 and $3 \mathrm{~mm}$ were advanced up to 12 and $15.7 \%$, respectively, by raising the corrugation angle. In addition, the toughness of the models infilled plate thickness of 2 and $3 \mathrm{~mm}$ were also enhanced up to 14.8 and $19.4 \%$, one after another, with the increase of the corrugation angle from $30^{\circ}$ to $120^{\circ}$.

- According to the results of the models with various $\mathrm{H} / \mathrm{B}$ ratios, reducing $\mathrm{H} / \mathrm{B}$ ratio from 1.2 to 0.5 can improve the ultimate loads, energy dissipation capacities, and toughness of the models up to 119.2, 108.8 and $113 \%$, respectively. Moreover, it was found out that increasing corrugation angle can be more effective in the models with lower $\mathrm{H} / \mathrm{B}$ ratio. For example, the ultimate load, energy dissipation capacity and toughness of C120-2-0.5 were 13.2, 71.4 and $22.5 \%$ higher than those of C30-2-0.5. Meanwhile, the ultimate load, energy dissipation capacity and toughness of C120-2-1.2 were 2.2, 21.4 and $7.6 \%$ higher than those of $\mathrm{C} 30-2-1.2$, respectively.
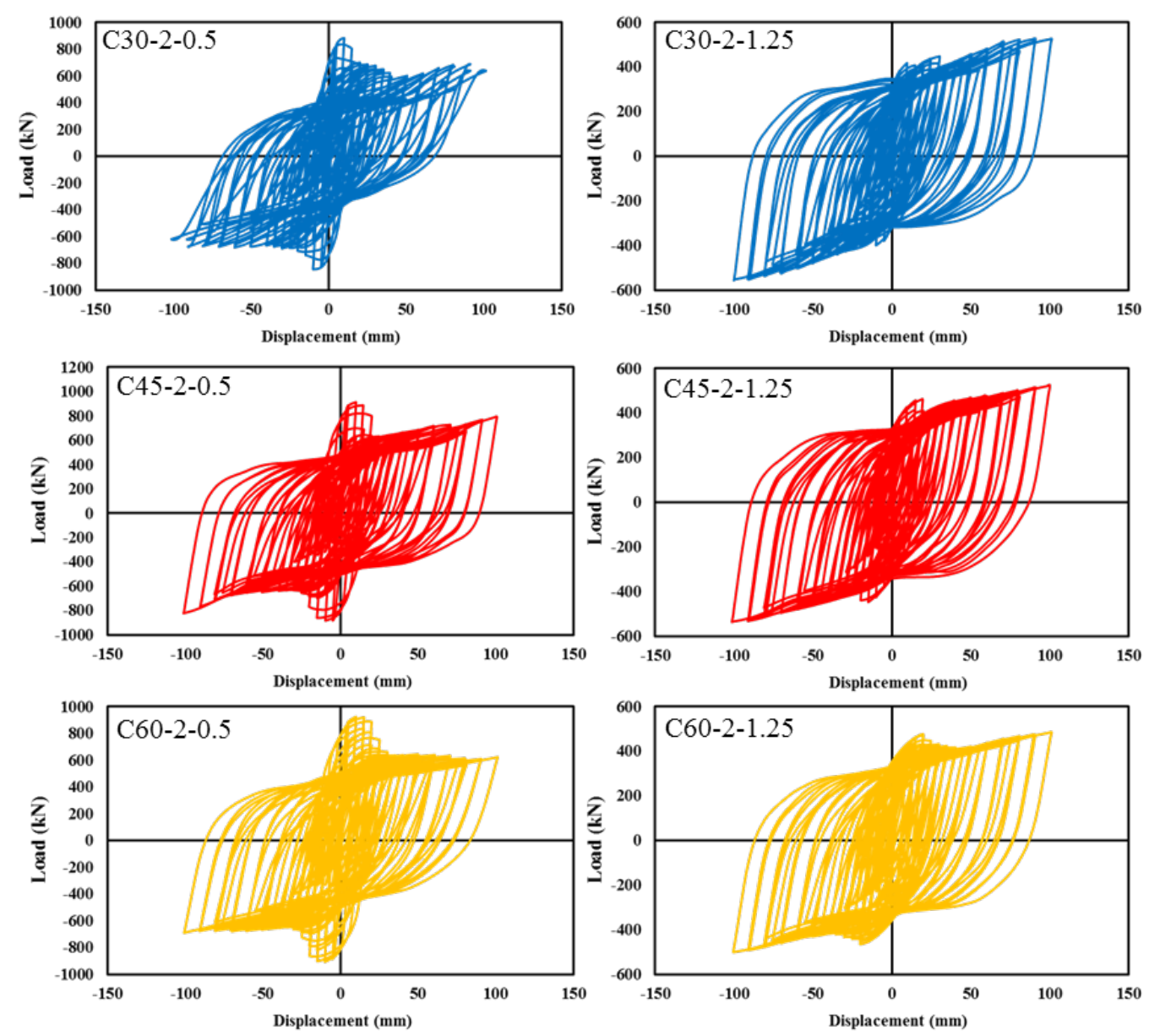

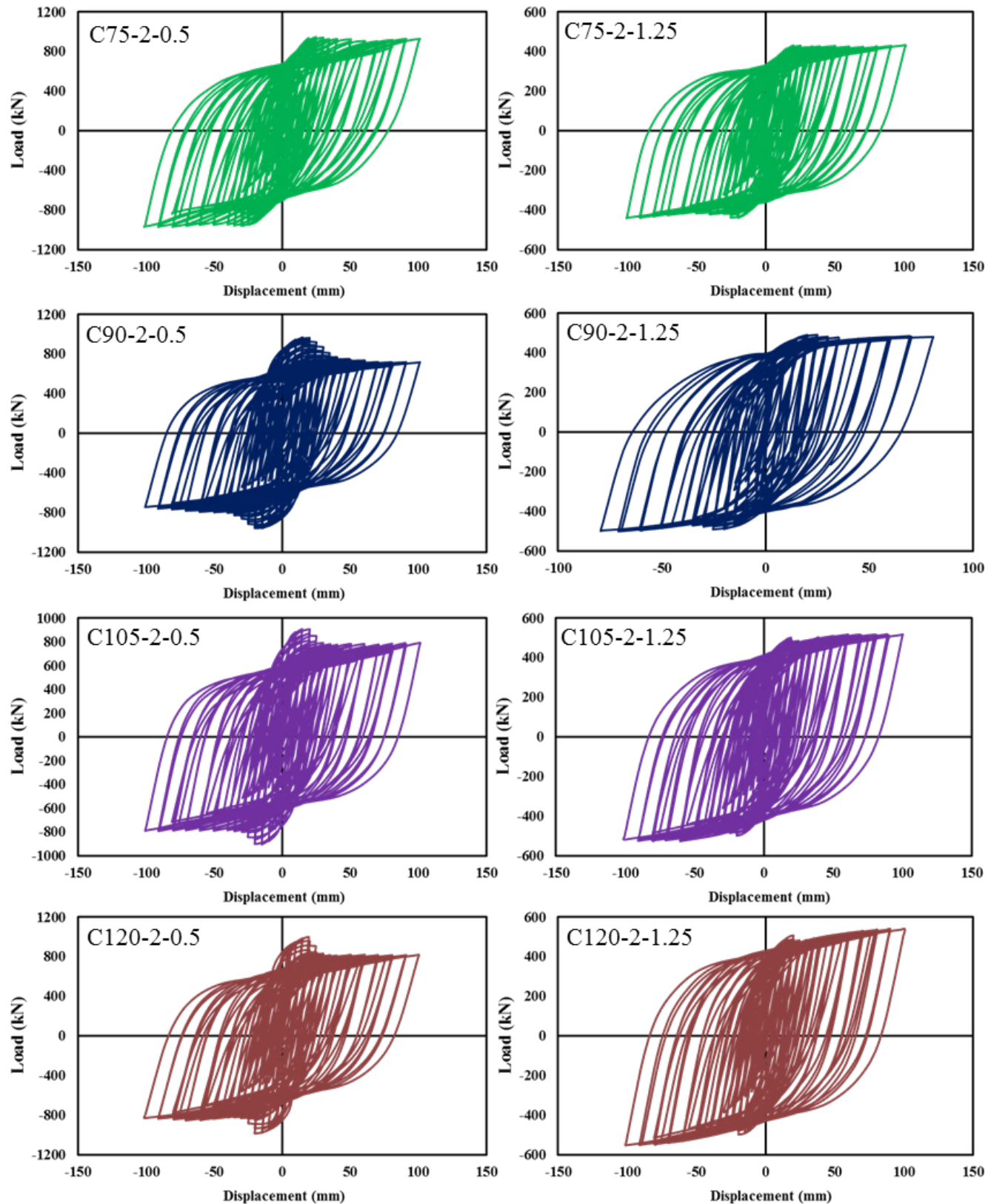

Figure 16. Hysteresis behavior of the FE models with different $\mathrm{H} / \mathrm{B}$ ratios

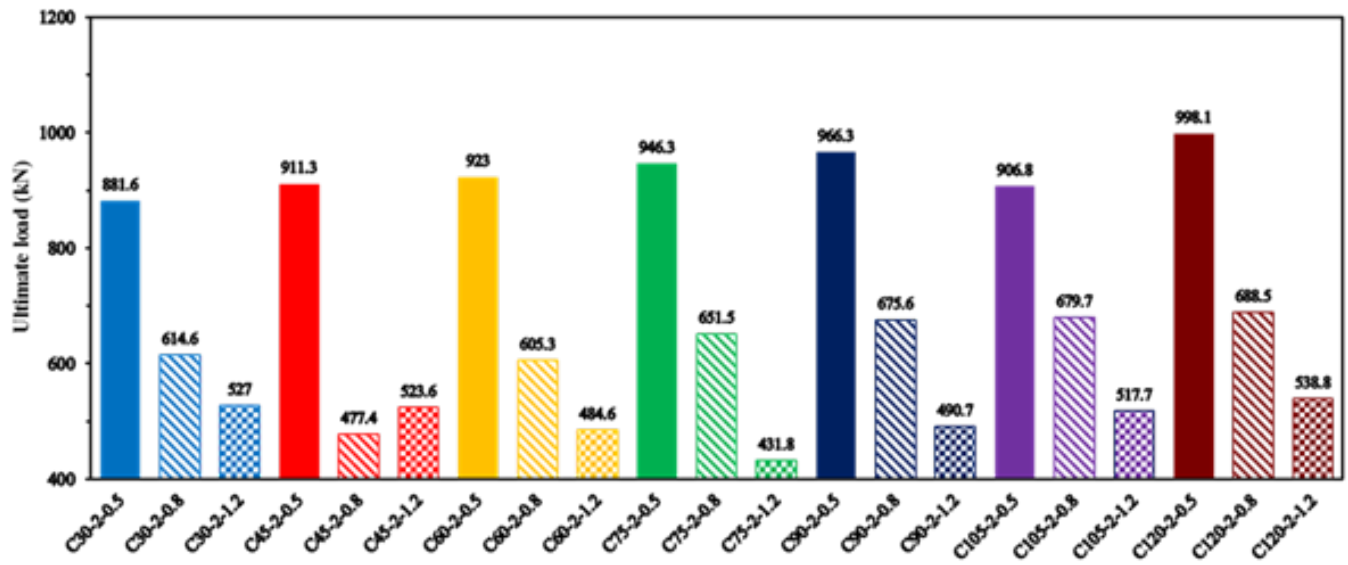

Figure 17. Ultimate loads of the FE models with different $\mathrm{H} / \mathrm{B}$ ratios 


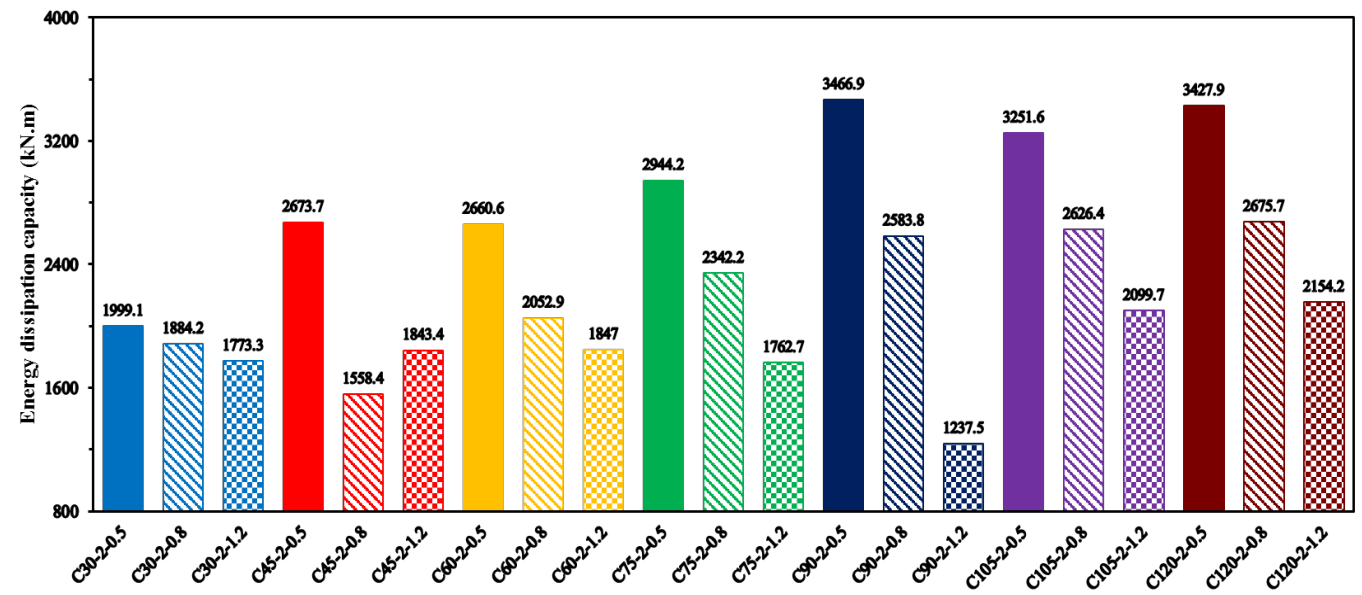

Figure 18. Energy dissipation capacities of the FE models with different $\mathrm{H} / \mathrm{B}$ ratios

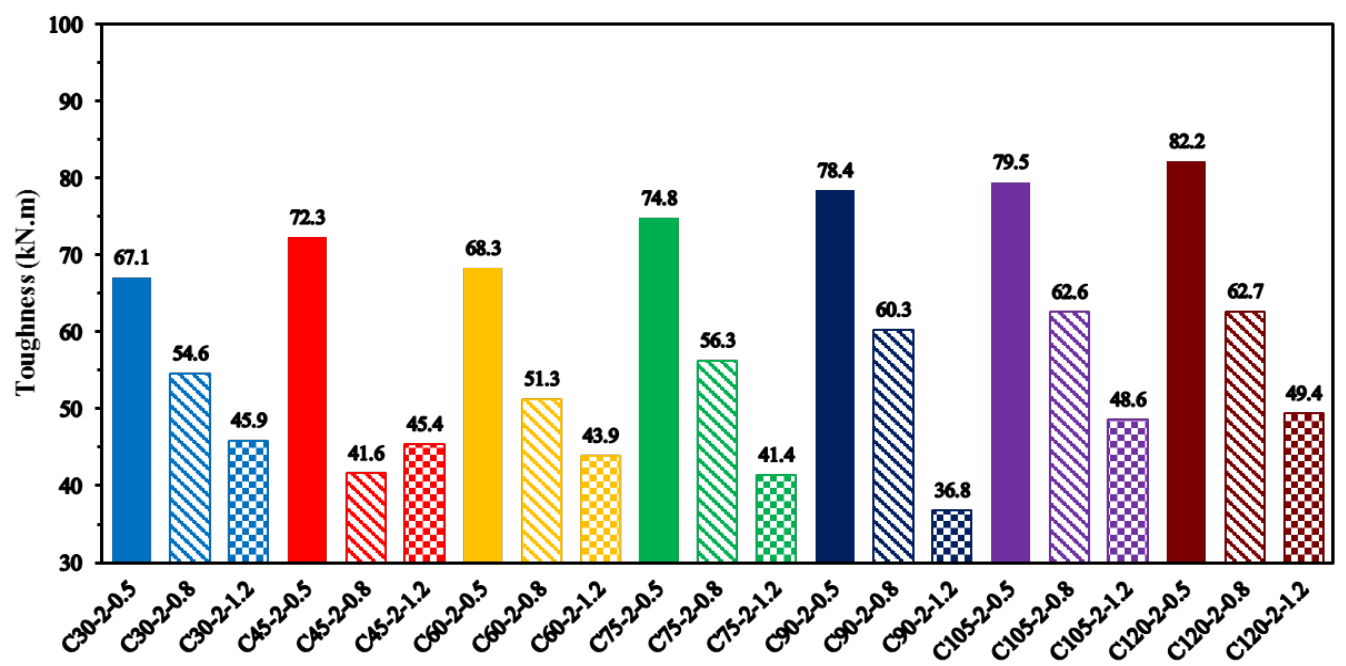

Figure 19. Toughness of the FE models with different $\mathrm{H} / \mathrm{B}$ ratios

\section{REFERENCES}

[1] E. Hosseinpour, S. Baharom, Y. Yadollahi. Evaluation of Steel Shear Walls Behavior with Sinusoidal and Trapezoidal Corrugated Plates, Adv. Civ. Eng., Vol. 2015, 163-715, 2015.

[2] S.J. Hilo, W.H.W. Badaruzzaman, S.A. Osman, A.W. Al-Zand. Structural behavior of composite wall systems strengthened with embedded cold-formed steel tube, Thin-Walled Struct., Vol. 98, 607-616, 2016.

[3] S. Jasim Hilo, W.H. Wan Badaruzzaman, S.A. Osman, A.W. Al Zand. Axial load behavior of acomposite wall strengthened with an embedded octagon cold-formed steel, In Proceedings of the Applied Mechanics and Materials, Trans Tech Publ, 437-441, 2015.

[4] Y. Yadollahi, I. Pakar, M. Bayat. Evaluation and comparison of behavior of corrugated steel plate shear walls, Lat. Am. J. Solids Struct., Vol. 12, 763-786, 2015.
[5] M.M. Ali, S.A. Osman, O.A. Husam, A.W. Al-Zand. Numerical study of the cyclic behavior of steel plate shear wall systems (SPSWs) with differently shaped openings, Steel Compos. Struct., Vol. 26, 361-373, 2018.

[6] M. Shariati, S.S. Faegh, P. Mehrabi, S. Bahavarnia, Y. Zandi, D.R. Masoom, A. Toghroli, N.T. Trung, M.N.A. Salih. Numerical study on the structural performance of corrugated low yield point steel plate shear walls with circular openings, Steel Compos. Struct., Vol. 33, 569-581, 2019.

[7] L. Lu-Jing, P. Xiao-Tong, Y. Tao-Chun. Study on lateral-force resistance performance of cross-slanted corrugated steel plate shear wall, In Proceedings of the Journal of Physics: Conference Series, IOP Publishing, 22070, 2019.

[8] M. Bahrebar, J.B.P. Lim, G.C. Clifton, T. Zirakian, A. Shahmohammadi, M. Hajsadeghi. Perforated steel plate shear walls with curved corrugated webs under cyclic loading. In Proceedings of the Structures, Elsevier, Vol. 24, 600-609, 2020.

[9] O. Bamshad, M. Ghassemieh. Development of Modified Ibarra-Krawinkler Deterioration Model for One-Story Steel Plate Shear Wall. Int. J. Steel Struct., Vol. 20, 1730-1754, 
2020.

[10] J. Fang, W. Bao, F. Ren, T. Guan, G. Xue, J. Jiang. Experimental study of hysteretic behavior of semi-rigid frame with a corrugated plate, J. Constr. Steel Res., Vol. 174, $106289,2020$.

[11] E. Eltayeb, X. Ma, Y. Zhuge, O. Youssf, J.E. Mills, J. Xiao, A. Singh. Structural performance of composite panels made of profiled steel skins and foam rubberised concrete under axial compressive loads, Eng. Struct., Vol. 211, 110448, 2020 .

[12] S.J. Hilo, W.H.W. Badaruzzaman, S.A. Osman, A.W. Al-Zand, M. Samir, Q.A. Hasan. A state-of-the-art review on double-skinned composite wall systems, Thin-Walled Struct., Vol. 97, 74-100, 2015.

[13] F. Emami, M. Mofid, A. Vafai. Experimental study on cyclic behavior of trapezoidally corrugated steel shear walls, Eng. Struct., Vol. 48, 750-762, 2013.

[14] F. Emami, M. Mofid. On the hysteretic behavior of trapezoidally corrugated steel shear walls, Struct. Des. Tall Spec. Build., Vol. 23, 94-104, 2014.

[15] M. Leblouba, M.T. Junaid, S. Barakat, S. Altoubat, M. Maalej. Shear buckling and stress distribution in trapezoidal web corrugated steel beams, Thin-Walled Struct., Vol. 113, 13-26, 2017.

[16] L. Hosseinzadeh, F. Emami, M. Mofid. Experimental investigation on the behavior of corrugated steel shear wall subjected to the different angle of trapezoidal plate, Struct. Des. Tall Spec. Build., Vol. 26, e1390, 2017.

[17] H. Kalali, M. Hajsadeghi, T. Zirakian, F.J. Alaee. Hysteretic performance of SPSWs with trapezoidally horizontal corrugated web-plates, Steel Compos. Struct., Vol. 19, 277 292,2015

[18] M. Bahrebar, T. Zirakian, M. Hajsadeghi. Nonlinear buckling analysis of steel plate shear walls with trapezoidally-corrugated and perforated infill plates, In Proceedings of the Proceedings of the Annual Stability Conference, Structural Stability Research Council, 2015.

[19] S.D. Shon, M.N. Yoo, S.J. Lee, J.W. Kang. A Comparative Study on Shear Buckling and Interactive Buckling Characteristics of Trapezoidal and Sinusoidal Corrugated
Steel Plate, J. Archit. Inst. Korea Struct. Constr., Vol. 31, 39-46, 2015.

[20] J.Z. Tong, Y.L. Guo. Elastic buckling behavior of steel trapezoidal corrugated shear walls with vertical stiffeners, Thin-Walled Struct., Vol. 95, 31-39, 2015.

[21] M. Bahrebar, M.Z. Kabir, M. Hajsadeghi, T. Zirakian, J.B.P. Lim. Structural performance of steel plate shear walls with trapezoidal corrugations and centrally-placed square perforations, Int. J. Steel Struct., Vol. 16, 845-855, 2016.

[22] M. Bahrebar, M.Z. Kabir, M. Hajsadeghi, T. Zirakian J.B.P. Lim. Structural performance assessment of trapezoidally-co rrugated and centrally-perforated steel plate shear walls, J. Constr. Steel Res., Vol. 122, 584-594, 2016.

[23] Y. Ding, E.F. Deng, L. Zong, X.M. Dai, N. Lou, Y. Chen. Cyclic tests on corrugated steel plate shear walls with openings in modularized-constructions, J. Constr. steel Res., Vol. 138, 675-691, 2017.

[24] S. Shon, M. Yoo, S. Lee. An experimental study on the shear hysteresis and energy dissipation of the steel frame with a trapezoidal-corrugated steel plate, Materials (Basel), Vol. 10, No.3, 261, 2017.

[25] Zefry Darmawan , Dwi Hadi S , Debrina Puspita A , Shigeyuki Haruyama, Oke Oktavianty. Bending Behavior on Beam with Supporting Part, Civil Engineering and Architecture, Vol. 8, No. 1, 21 - 25, 2020. DOI: 10.13189/cea.2020.080103

[26] Yeong-Min Kim. Structural Analysis and Conceptual Seismic Design of Large-span Korean Traditional Timber Structure, Civil Engineering and Architecture, Vol. 8, No. 2, 154 - 165, 2020. DOI: 10.13189/cea.2020.080213

[27] M. Ansari, M. Z. Jeddi, W. H. W. Badaruzzaman, M. M. Tahir, S. A. Osman, E. Hosseinpour. A numerical investigation on the through rib stiffener beam to concrete-filled steel tube column connections subjected to cyclic loading, Engineering Science and Technology, an International Journal, 2020.

[28] L. Hosseinzadeh, M. Mofid, A. Aziminejad, F. Emami. Elastic interactive buckling strength of corrugated steel shear wall under pure shear force, Struct. Des. Tall Spec. Build. Vol. 26, No. 8, 2017. 